\title{
Branquitude e progresso: a Liga Paulista de Higiene Mental e os discursos paulistanos na contemporaneidade
}

\section{Whiteness and ideas on progress: the "Liga Paulista de Higiene Mental" and current racial conceptions in São Paulo}

\author{
Lia Novaes Serra* \\ Universidade de São Paulo - USP, São Paulo, São Paulo, Brasil \\ Lia Vainer Schucman** \\ Universidade de São Paulo - USP, São Paulo, São Paulo, Brasil
}

\begin{abstract}
RESUMO
O objetivo deste artigo é analisar como a política racial implementada na cidade de São Paulo, no início do século 20, se reatualiza hoje nas ideias e nas representações de progresso e desenvolvimento na metrópole paulistana. Primeiramente, investigamos o arcabouço teórico dos projetos eugenistas elaborados nas primeiras décadas do século 20, pelos psiquiatras da "Liga Paulista de Higiene Mental" (LPHM). Como procedimento de pesquisa, analisamos parte dos documentos da LPHM sobre raça e eugenia, catalogados no "Museu Histórico Prof. Carlos da Silva Lacaz", da Faculdade de Medicina da Universidade de São Paulo. Posteriormente, com o intuito de compreender as possíveis consequências desses projetos nas atuais concepções raciais de São Paulo, analisamos algumas entrevistas com paulistanos de diferentes classes sociais, idade e gênero que se auto identificaram como brancos. Os resultados apontaram que muitos dos entrevistados ainda se apropriam dos significados compartilhados sobre superioridade e "pureza racial" branca. Pode-se pensar, a partir das analises das entrevistas, que atualmente nossa sociedade desenvolveu um sistema hierárquico silencioso de atribuição de status social que desvaloriza as pessoas na proporção direta em que estes se afastam do modelo ideal de branquitude.
\end{abstract}

Palavras-chave: branquitude, Liga Paulista de Higiene Mental, história da psicologia, racismo, psicologia social.

\begin{abstract}
The purpose of this article is to depict how the racial policy settled in the city of São Paulo, at the beginning of the 20th century, still echoes today over the ideas on urban progress and city development. First, we describe the basic conceptual framework of the eugenics projects, addressed over the first decades of the 20th century by the psychiatrists in charge of the "Liga Paulista de Higiene Mental" (LPHM). As an initial research approach, we analyze the LPHM documents on race and eugenics, retrieved from the "Museu Histórico Prof. Carlos da Silva Lacaz", at the Faculdade de Medicina in Universidade de São Paulo. Then, in order to understand the possible
\end{abstract}


consequences of these projects over the current general racial conceptions in São Paulo, we expound a small set of interviews with local individuals, from different social layers, age and gender, who identify themselves as whites. We notice that most of these self declared white interviewees arrogate some of the ancient ideas on white racial superiority and "white purity" taken from that time.

Keywords: whiteness, Paulista Mental Health League, history of psychology, racism, social psychology.

\section{I ntrodução}

Este artigo tem como objetivo compreender como a política racial implementada na cidade de São Paulo, no inicio do século XX, ecoa e produz sentidos nos ideais e nas representações de progresso e desenvolvimento da metrópole paulistana, na atualidade. Branquitude se refere ao lugar de poder simbólico e material que sujeitos considerados brancos se veem ocupando globalmente e localmente nas sociedades ocidentais. Como outras localizações raciais, não tem significado intrínseco, mas apenas significados socialmente construídos. Nessas condições, os significados da branquitude têm camadas complexas e variam topicamente, bem como entre os locais. Além disso, seus significados podem parecer simultaneamente maleáveis e inflexíveis (FRANKENBERG, 2004). Portanto, a branquitude precisa ser considerada "como a posição do sujeito, surgida na confluência de eventos históricos e políticos determináveis" (STEYN, 2004, p. 121).

Neste sentido, este artigo se propõe a compreender como o ideal de branquitude foi construído na cidade de São Paulo pelos projetos eugenistas erigidos pelos psiquiatras da Liga Paulista de Higiene Mental (LPHM) e suas possíveis repercussões nas micropolíticas cotidianas da atualidade. Para tanto, será necessário fazer um recorte teórico conceitual dos projetos eugenistas dessa corrente psiquiátrica paulistana, nas primeiras décadas do século $X X$, para então nos voltarmos para as formas de apropriações desta construção discursiva nos sujeitos contemporâneos.

\subsection{Liga Paulista de Higiene Mental}

Tendo como referência a Liga Brasileira de Higiene Mental (LBHM), em 1926, os médicos Antonio Carlos Pacheco e Silva, Geraldo de Paula Souza, Enjolras Vampré, Marcondes Viera, Cantídio de Moura Campos, Fausto Guerner e Ferraz Alvim, entre outros, fundaram a Liga Paulista de Higiene Mental, sediada no Hospital do Juquery (ANTUNES; 2002).

Focada em atividades educativas, a Liga Paulista divulgava os princípios da higiene mental para a população por via radiofônica, 
pela publicação de artigos em jornais e periódicos, pela distribuição de folhetos e cartilhas - nos moldes estadunidenses - e também em publicações especializadas dirigidas aos profissionais da área (MARQUES, 1994).

A LPHM nasce com os mesmos princípios que a LBHM se propusera inicialmente, quais sejam, os de aprimorar a assistência psiquiátrica no país. Entretanto, os caminhos desenhados para tal já levavam em conta a ampliação do trabalho exercido pelos médicos, a quem caberia ocupar o poder público para a criação e a fiscalização de seus interesses, divulgar medidas preventivas das doenças psíquicas para todos os cidadãos, pautar suas ações pelas diretrizes da eugenia e acompanhar seu desenvolvimento no Brasil e no mundo. Para Pacheco e Silva ([entre 1934 e 1954], p. 2), as intenções da LPHM e os meios de que se deveria valer para cumprir seus objetivos eram:

- Prevenção das doenças nervosas e mentais pela observância dos princípios da higiene geral e especial do sistema nervoso;

- Proteção e amparo do meio social aos egressos dos manicômios e aos deficientes mentais;

- Melhoria progressiva nos meios de assistir e tratar os doentes mentais em asilos públicos, particulares ou fora deles;

- Atuar junto aos poderes públicos estaduais e municipais, sugerindo medidas e obtendo realizações;

- Propagar junto à população do Estado as modernas ideias sobre profilaxia mental;

- Estudar todos os problemas relativos à higiene do sistema nervoso;

- Publicar periodicamente os seus trabalhos em revista por ela mantida e que se distribuirá entre seus associados;

- Promover a realização do Congresso de Eugenia, onde serão discutidas e votadas as questões de higiene mental;

- Manter relações com associações congêneres nacionais e estrangeiras, cujos objetivos coincidam com o seu.

Não se pode, entretanto, caracterizar o movimento higienista paulista como homogêneo. De acordo com Antunes (2002), havia duas correntes principais. Uma delas adequava o discurso higienista à necessidade de afirmar a psiquiatria como prática médica. Sendo considerada medicina, a psiquiatria ganhava cientificidade e status para propor normas higiênicas para todos. Essa direção, de tendência eugênica, era representada por Pacheco e Silva, Ferraz Alvim e outros.

O outro posicionamento da higiene mental paulista era fortemente marcado por influências da psicanálise. Tendo à frente Durval Marcondes e, posteriormente, Mário Yahn, as diretrizes higiênicas desse grupo se implantaram no Serviço de Higiene Mental Escolar, inserindo-se em atendimentos ambulatoriais, com equipes 
profissionais e terapêutica psicológica. Essa vertente teve início com Franco da Rocha, quando este juntamente com Marcondes, introduziu em São Paulo as ideias psicanalíticas, em 1919 (ANTUNES, 2002).

Para este artigo nos interessa, sobretudo, os caminhos do primeiro grupo - desvendar o "espírito" da higiene pela profilaxia e por ações eugênicas decorrentes das escolhas desses psiquiatras "um pouco mais radicais". Pode-se perceber que eles receberam influências das teorias e dos pensamentos que assolavam os EUA e a Europa. Dos EUA, deve-se destacar o pioneirismo deste país pela criação do primeiro Comitê de Higiene Mental, em 1909, e o grande investimento que fizeram para a divulgação dos preceitos higienistas (MARINHO, 2001).

Exemplo da presença maciça dos EUA, em São Paulo, foi o acordo fechado entre a Fundação Rockefeller e a Faculdade de Medicina e Cirurgia, em 1916. O acerto dava à agência poderes para intervenções científicas. Segundo Mota (2005[a], p. 200), a Fundação pretendia ser representante da "ciência e do bem da humanidade e buscava adesão a seus propósitos filantrópicos pragmáticos e conservadores".

O acordo também contribuiu para a criação do Instituto de Higiene, o Instituto de Patologia e, posteriormente, outros empreendimentos. O Instituto, por exemplo, formou médicos especialistas e educadores sanitários que ocuparam cargos públicos para além da pesquisa disseminar os princípios da educação sanitária por meio da eugenia e do higienismo (GONÇALVES, 2010).

Para Marinho (2004) a presença da cultura norte americana, efetivada pela Fundação Rockefeller demonstrou um grande deslocamento da tradição francesa vigente, que era "assentada na clínica e no diagnóstico baseado em sintomas, centrada em relações individualizadas entre médico-paciente, para procedimentos ajustados às práticas norte-americanas de viés mais efetivamente intervencionista" ( $p .153$ ).

Além disso, há citações incessantes dos psiquiatras paulistas em relação ao andamento das ações higiênicas no $E A^{1}$, encontradas, principalmente, no Boletim de Higiene Mental, na Resenha Clínicocientífica da Faculdade de Medicina da Universidade de São Paulo e nas Teses de Doutoramento da antiga Faculdade de Medicina e Cirurgia de São Paulo. É necessário registrar que a influência dos EUA promoveu, também, um grande encontro com a doutrina eugenistas e suas práticas interventivas (MARINHO, 2001).

O psiquiatra Paulo de Azevedo Antunes, em sua tese de doutoramento defendida na Faculdade de Medicina e Cirurgia de São Paulo, em 1926, intitulada Eugenia e Immigração faz inúmeras referências aos EUA, apontando o modo exemplar com que esse país lidou com o alcoolismo (suprimindo o comércio do álcool); com a censura matrimonial (proibindo casamento entre pessoas 
"abastardas" e entre brancos e negros); com a rigorosa seleção de imigração (permitindo apenas a entrada de brancos no país); os modelos legislativos em vigor (que poderiam ser repetido no Brasil); e por fim, a excelência em pesquisa realizadas pelos Institutos estadunidenses.

Monteleone (1929) em Os cinco problemas da eugenia brasileira, contextualiza os problemas da Eugenia nos principais países: Inglaterra, Estados Unidos, França, Suécia, Noruega, Dinamarca, Rússia, I ugoslávia, México, Alemanha, Argentina, Bélgica, Itália, Áustria e Holanda. É de se notar que, Monteleone despende mais atenção a situação dos EUA do que aos outros países. O autor enumerou os inúmeros passos criados pelo país para efetivar as medidas eugênicas. Enfatiza, ainda, a realização do aumento de casamento e nascimento das "classes superiores", a maior segregação entre as classes, as esterilizações, a regulamentação da imigração, a seleção natural, entre outros.

Por outro lado, os países europeus também aparecem como outra grande influencia do pensamento higienista e eugenistas, para A LPHM. Para se ter uma idéia, ao participar, junto com outros representantes brasileiros do II Congresso de Higiene Mental, financiados pelo Ministro da Educação e Saúde, Gustavo Capanema, o médico Pacheco e Silva relata as sessões de trabalhos apresentados no congresso, principalmente, sobre a eugenia. Mostra-se de acordo com as diretrizes tomadas pela Alemanha para tratar as doenças mentais de origem hereditária, que propõe impedir a propagação de células sexuais "taradas" pela esterilização e outros métodos eugênicos eliminatórios. Relata o que ouviu nessa sessão:

As condições fundamentais de uma seleção eugênica devem ficar afetas ao serviço de saúde pública, inspiradas em princípios eugênicos e entregues a um corpo de médicos bem preparados tanto na diagnose como na heredo biologia humana, sem dispensar o concurso de funcionários do Estado com conhecimentos de Eugenia. Além disso, torna-se indispensável propaganda intensa no seio da população em favor das idéias eugênicas (PACHECO E SILVA, [ca. 1937], p. $5)$.

\subsection{Uma nova ciência: a eugenia}

Em diversos documentos da LPHM, encontram-se os princípios da eugenia sendo referidos como "modernas ideias" para atuar sobre a população paulista. Numa palestra proferida pela rádio Difusora em 1936 sobre exames pré-nupciais, esclarece a importância de os jovens não cometerem os mesmos erros das gerações anteriores em relação ao matrimônio. Para tanto, era preciso que aplicassem os 
ensinamentos da higiene mental e da eugenia: "No ideal eugênico, na formação de uma prole sadia, bem constituída fisicamente e melhor dotada espiritualmente, repousa não apenas a felicidade de um lar, mas o futuro da nacionalidade" (PACHECO E SILVA, 1936, s/p.).

Nessa mesma palestra, Pacheco e Silva comenta o Artigo 145 da Nova Constituição Brasileira, que ainda aguardava aprovação, e pretendia regularizar o exame pré-nupcial, tornando-o obrigatório a todos os nubentes. Para os higienistas mais radicais, esse exame seria uma prova de que o casal gozava de sanidade física e mental para a gestação. Esse tipo de procedimento já era muito utilizado em países europeus e nos EUA, onde demonstrava que "as nações mais fortes, que dão melhor exemplo da sua vitalidade, são as que mais zelam pela saúde dos elementos renovadores, assegurando um futuro melhor para cada geração que surge" (PACHECO E SILVA, 1936, s/p.).

A eugenia era tomada pelos psiquiatras da Liga Paulista como um programa de ações que potencialmente implementaria normas sociais entre a população. Dessa forma, o discurso higienista era readaptado para a inclusão das propostas eugênicas que legitimavam as práticas psiquiátricas na sociedade. Reafirmar a importância da psiquiatria era garantir aos especialistas a cientificidade e a autonomia de suas intervenções políticas (ANTUNES, 2002). Nesse sentido, Pacheco e Silva proclama:

Urge, agora, cuidar das gerações novas, procurar mais bem dotá-las física e psiquicamente, aperfeiçoando as qualidades inatas, fazendo reviver as energias latentes, racionalizando os modernos processos científicos, em resumo - aplicando os princípios dessa nova ciência que é a Eugenia (PACHECO E SILVA, [ca. 1934], p. 2).

A eugenia foi introduzida no Brasil pela elite intelectual ao final do século XIX, e encontrou aqui uma ótima aceitação no meio médico. Admirados pelo pensamento em voga na Europa, "homens da sciência" como Nina Rodrigues, Euclides da Cunha e Silvio Romero aderiram prontamente à eugenia e a outras teorias raciais congêneres, que, em grande medidas, eram utilizadas para extinguir as desigualdades políticas e sociais no Brasil (MARQUES, 1994; REIS, 2000).

Apoiando-se na biologia e buscando redimensionar a problemática das raças e as desigualdades sociais, a eugenia pode ser considerada uma nova forma de intervenção da higiene mental, num momento em que não era mais possível negar os ideais republicanos de igualdade à maioria da população negra e mestiça do país. De modo geral, a higiene mental pretendia aplacar a insatisfação da população por meio da disciplina e de ações normativas, cuja legitimidade se 
fundava na eugenia como instrumento científico ideal (MARQUES, 1994).

Originado do grego, o termo "eugenia" significa, em tradução livre, boa geração (eu=bom, genia=geração); foi usado pela primeira vez pelo inglês Francis Galton em 1869, correspondendo "às possíveis aplicações sociais do conhecimento da hereditariedade para obter-se uma desejada melhor reprodução" (STEPAN, 2005, p. 9). Formado em medicina, e grande estudioso na área de estatística, Galton defendeu a tese de que a hereditariedade determinava os traços físicos e as capacidades mentais; seus estudos estatísticos e genealógicos concorreram para justificar a intervenção médica na evolução humana e no aperfeiçoamento da espécie (LOBO, 2001). Como movimento social e científico, a eugenia esteve presente em diferentes países (SCHWARCZ, 2008).

A hereditariedade também foi tema do naturalista britânico Charles Darwin, cuja pesquisa serviu de fundamentação para os estudos de Galton. Em seu reconhecido livro A origem das espécies (1859), Darwin dava provas científicas de que todas as espécies, inclusive 0 homem, tinham ascendentes comuns. A aceitação das teorias darwinistas encontrou maior dificuldade porque contradizia o mito de origem, a cosmogonia, encontrado no Antigo Testamento, matriz do judaísmo e, depois, do cristianismo.

No Brasil, houve uma grande resistência às ideias de Darwin, assim como em outros países tal como França, Inglaterra, Alemanha e EUA. Por outro lado, embora tenha havido também um consenso em torno da ideia de que as espécies estavam em constante transformação, instaurou-se uma controvérsia em relação ao modo pelo qual ocorriam essas transformações (GUALTIERI, 2003). É importante ressaltar que várias interpretações das ideias darwinistas foram aplicadas à análise dos processos sociais do país, muitas vezes para justificar diversas formas de dominação.

De acordo com Bizzo (1995), a teoria darwinista auxiliou a formação do pensamento racista, como fez Spencer (1820-1903) ao advogar que somente os indivíduos mais promissores deveriam se reproduzir, já que os aspectos físicos e intelectuais eram transmitidos de geração a geração. Nossos intelectuais nas primeiras décadas do século XX aclamaram tais teóricos, que fundamentavam a crença numa "superioridade branca" - isto foi denominado de "evolucionismo social".

Eles acreditavam que a aplicação da teoria evolutiva proposta por Darwin iria, em séculos, aperfeiçoar a raça humana, permanecendo apenas os mais favorecidos física e intelectualmente. No entanto, a "ciência" poderia acelerar essa melhoria da raça, através de medidas preventivas - como o incentivo à imigração europeia para clarear a população - ou impeditivas - como a esterilização dos "degenerados" (MONTELEONE, 1929). 
Na tese de doutorado do médico Paulo C. A. Antunes, de 1926, também se encontram convicções eugenistas, sobre a supremacia branca, justificadas pelas ideias darwinistas; mas dessa vez pelo viés da inteligência. O autor afirma que, sendo a inteligência hereditária, assim como havia diferença entre os cães quanto a isso, o mesmo acontece entre os seres humanos.

\begin{abstract}
A intelligencia será hereditária? Evidentemente sim, pois não poderá constituir a excepção. Si o timbre da voz, funcção da larynge, é hereditário, porque a intelligencia, função de cérebro, não ha de ser? Entre os cães, por exemplo, é notória a differença de intelligencia entre as suas diferentes raças. No homem também se observa o mesmo: o filho do negro herda de seus paes uma capacidade intellectual inferior á que nós herdamos dos nossos (ANTUNES, 1926, p. 14).
\end{abstract}

As teorias sobre a importância da hereditariedade e eugenia se desenvolveram no mesmo período, exemplo disso é a publicação Hereditary genius (1869), de Galton. Nessa obra, o autor defende a ideia de que as vocações e os talentos são transmitidos entre as gerações, assim como os aspectos físicos também o são. A eugenia argumenta que as raças deveriam permanecer definidas para que fosse possível encontrar um padrão, um representante típico de cada uma, e, portanto, a miscigenação deveria ser impedida já que colocaria a perder toda compreensão dos aspectos intelectuais característicos das raças "puras" (BIZZO, 1995).

Darwin, primo de Galton, também aderiu as teses eugênicas, assim como grande parte da elite científica da época. Em The variation of animals and plants under domestication (1868), Darwin sustenta a hipótese que toda mudança sofrida no corpo era transmitida aos órgãos reprodutores e repassada a geração seguinte já com as modificações, assim, o exame físico dos indivíduos garantiriam quais poderiam dar continuidade de suas heranças à prole (BIZZO, 1995; COLLICHIO, 1988; DOMINGUES, 2003).

Mesmo com as dificuldades de comprovação dos pressupostos eugênicos, o modelo de transmissão hereditária propagado por Galton, Darwin e outros cientistas impulsionou a divulgação do ideal eugênico. Pode-se perceber a influência do programa eugênico em diversos países. Nos estudos de Stepan (2005), por exemplo, a eugenia latino-americana é documentada antes mesmo da Primeira Guerra Mundial, pois em 1914, está presente na tese de Alexandre Tepedino, da Faculdade de Medicina do Rio de Janeiro.

A Primeira Guerra Mundial teve um impacto importante na América Latina, em especial no Brasil, que se posicionou do lado da Tríplice Entente - composta pelo Império Britânico, França e Império Russo e precisava que sua população estivesse de prontidão e disciplinada 
para a guerra. Além disso, ainda estavam em curso as consequências imediatas da criação da República, do fim da escravidão e da abertura do país à imigração europeia em larga escala (COSTA, 2007; STEPAN, 2005; DIWAN, 2007).

De acordo com Costa (2007), a eugenia como ciência auxiliou a intelectualidade brasileira a justificar as crises das primeiras décadas do regime republicano, que enfrentava a abolição da escravatura, o êxodo rural, a industrialização e a imigração europeia. Pautada pelo discurso da sociedade democrática e dos direitos iguais para todos, a República precisava justificar as evidentes desigualdades. Assim, as explicações eugênicas vieram muito a propósito, e suas prédicas tiveram muito eco entre os intelectuais brasileiros, que imputavam o fracasso da igualdade republicana ao clima tropical e à miscigenação de raças inferiores na constituição da população.

Para Mota \& Schairaiber (2009), a higiene mental procurou mapear todas as questões relativas às ações eugênicas com o propósito de estudar e validar cientificamente as determinações hereditárias que pretendiam melhorar a vida física e psíquica da população:

As estratégias eugênicas nasciam de um pensamento modernizador e cientificista do século XIX, tendo em suas bases intervenções de cunho científico capazes de alterar a composição humana considerada como um "desvio" do curso natural da história. [...] Propunham, dessa maneira, constituir homens de "raça elevada" a partir da utilização de estratégias tidas como científicas e capazes de impedir a ameaça dos considerados fracos e inferiores na construção racial da nação (MOTA; SCHAIRAIBER, 2009, p. 196).

De acordo com Marques (1994), a eugenia fundamentada em pressupostos científicos confirmava as diferenças na população através da raça e ressaltava a periculosidade das classes pobres. Ao mesmo tempo em que constatava a degeneração racial e moral dos brasileiros, apontava o embranquecimento e todo o arsenal de intervenções genéticas, como saída para a constituição da "raça brasileira".

O caráter técnico-científico desfrutado pela eugenia como ciência do aperfeiçoamento da raça, portanto capaz de intervir sobre a população para constituí-la, excluí-la ou conformá-la, conferia-lhe o poder de costurar instâncias constitutivas do social as quais nem a higiene, nem a filantropia, nem a educação, isoladamente, tinham sido capazes de articular. Tratava-se de um discurso integrador das estratégias de controle sobre o sexo que não se impunham através da lei mas por meio do poder político de gerar e gerir a vida da população e da cidade, decorrendo daí a possibilidade de progresso biológico e social (MARQUES, 1994, p. 41). 
A primeira sociedade brasileira de eugenia surgiu em São Paulo, fundada em 1918 pelo renomado médico Renato Kehl, com o apoio do diretor da Faculdade de Medicina de São Paulo, Arnaldo de Viera Carvalho. A Sociedade Eugênica de São Paulo tinha 140 membros, dos quais a maior parte integrava a elite médica da cidade, e, apesar de ter sido bem aceita tanto entre os médicos como na imprensa, a instituição não se manteve após a morte de Arnaldo Vieira, presidente da SESP, e a mudança de Renato Kehl para o Rio de Janeiro em 1919 (REIS, 2000).

Insigne representante da eugenia, Kehl publicou mais de trinta livros sobre o tema. De acordo com Diwan, sua trajetória pode ser dividida em dois períodos. No primeiro, o médico defendia:

[...] a eugenia positiva, profilática, alinhada com os objetivos dos médicos sanitaristas. Essa fase contempla o período entre 1917 e 1928, desde a primeira palestra de Kehl na Associação Cristã de Moços até o retorno de sua viagem pela Europa, em especial pela Alemanha, onde entrou em contato com as políticas eugênicas em vigor naquele país (DIWAN, 2007, p. 125).

A segunda fase seria o momento de maior radicalização, em que ele passou a defender também métodos de esterilização e critérios para a imigração. Nesse momento, Kehl estaria fundamentado pela eugenia negativa que visava, entre outros objetivos, impedir o nascimento de indivíduos não-eugênicos através de ações restritivas como o controle do matrimônio, esterilizações de "degenerados" e abortos induzidos.

Pacheco e Silva, psiquiatra paulista do início do século $X X$, também menciona o êxito da eugenia entre os brasileiros, ao estudar a Etiologia das doenças mentais, texto em que pretende distinguir as diferentes causas das patologias mentais em predisposições gerais e individuais. Dentre as primeiras, afirma que a hereditariedade "é a causa das causas" e que muito se tem feito para investigar os avanços da eugenia:

Entre nós Kehl, Roxo, Austregésilo, Cunha Lopes e tantos outros teem se ocupado da eugenia. Nós também procuramos, fundando ligas, em publicações diversas, difundir os princípios básicos da higiene mental, sobretudo da eugenia, para que o povo possa tirar os benefícios decorrentes de seu conhecimento. Por isso pensamos incluir na Nova Carta Constitucional um dispositivo que obriga os poderes públicos a difundir a educação eugênica nas escolas e em todas as aglomerações (PACHECO E SILVA, [ca. 1934], p. 6). 
Em seu discurso como paraninfo da turma de 1938 da Faculdade de Medicina da Universidade de São Paulo, Pacheco e Silva aconselha aos novos médicos que não descuidem dos problemas étnicos do país, adquiridos pela catastrófica política de imigração, e enfatiza a política eugênica como saída para a melhoria da genética brasileira, aproximando-se das diretrizes da eugenia negativa.

\begin{abstract}
A higiene da raça, já o sabeis, repousa sobretudo em medidas eugênicas: uma raça é tanto melhor quanto maior for o números de famílias eugênicas, isto é, de componentes hereditariamente bem dotados. [...] A indiferença pelos problemas raciais, a inobservância das leis biológicas, o desprezo pela experiência ântropo-sociológica se fazem sentir cedo ou tarde sobretudo nas nações novas, com incalculáveis prejuízos para a coletividade (PACHECO E SILVA, 1939, p. 30/32).
\end{abstract}

Nesse ponto, o autor deixa claro que caberia aos novos médicos não apenas incentivar a união entre os "geneticamente favorecidos", como também intervir nas leis biológicas pela experiência antropossociológica. Marques (1994, p. 44), analisando esse texto, considera que os médicos políticos, poderiam, com o auxílio da "ciência" eugênica, (re)modelar os corpos físicos e sobretudo o corpo social, ao impor o lugar dos diferentes grupos na sociedade que só poderiam conquistar outras posições "assim que atingissem 0 branqueamento, a disciplina e a normalização".

\title{
2 Repercussões do projeto eugênico paulistano na atualidade
}

\subsection{A Pesquisa de campo}

A escolha da entrevista como recurso para buscar compreender como os sujeitos se apropriam do significado da raça e do projeto eugênico apresentado, anteriormente, decorreu por esta técnica apresentar a possibilidade do entrevistado transmitir oralmente ao entrevistador sua definição pessoal, significados e sentidos de seus atos, comportamentos, pensamentos e discursos sobre o tema. Além disso, a situação de entrevista provoca a lembranças de vivências que ao serem narradas podem ser reelaboradas e ganharem novos sentidos (NARITA, 2006). A entrevista é aqui compreendida como um processo de comunicação e interação entre pesquisador e pesquisado, no qual significados, interpretações e informações são produzidos.

O fato de um dos recortes dessa pesquisa se traduzir em investigar a categoria raça e os significados da branquitude na atualidade paulistana nos levou a estabelecer apenas dois critérios para escolher 
os sujeitos de pesquisa. O primeiro critério é que o sujeito entrevistado seja classificado como branco por ele mesmo e pelas pesquisadoras. E o segundo, é ter residência na cidade de São Paulo. É importante ressaltar que, a literatura sobre raça e racismo no Brasil e no exterior (GUIMARÃES, 1999; FRANKENBERG,2004) mostra que as categorias de gênero, classe e geração são também definidoras dos significados atribuídos à identidade racial. Portanto, como o intuito desta pesquisa é buscar a compreensão da categoria raça, consideramos relevante que o grupo pesquisado fosse investigado exatamente em sua heterogeneidade.

Neste sentido, é importante explicitar que uma das hipóteses é que a categoria raça presente no imaginário da população é ainda aquela produzida pela ciência moderna nos séculos $X I X$ e $X X$, e que teria a função de classificar a diversidade humana em grupos fisicamente contrastados, que têm características fenotípicas comuns, sendo estas tidas como responsáveis pela determinação das características psicológicas, morais, intelectuais e estéticas dos indivíduos dentro destes grupos, situando-se em uma escala de valores desiguais (MUNANGA, 2004).

Por isso, procuramos fazer um roteiro de entrevistas que delimitasse focos norteadores sobre o significado e o sentido de ser branco e a relação deste sentido com a categoria raça. Dessa forma, as perguntas foram construídas com o intuito de perceber se e como os sujeitos relacionavam características sobre a branquitude com características de progresso e civilização.

\subsubsection{Os entrevistados}

O fato de a entrevistadora ser considerada branca no contexto brasileiro e de ter sido socializada dentro da classe média paulistana, em que a maioria dos sujeitos se considera branca, facilitou a localização dos entrevistados para este fim perguntamos a conhecidos se estes tinham alguém que se interessaria em ser entrevistado para uma pesquisa de doutorado sobre branquitude ${ }^{2}$. Rapidamente, amigos de amigos se colocaram à disposição por e-mail e telefone. Para descrever os sujeitos, registramos nas entrevistas os seguintes dados: nome fictícios, idade, cidade de origem, profissão, autodefinição racial, autodefinição de classe social e a origem da família. Optamos por colocar nomes fictícios, já que a intenção desta pesquisa não é a de retratar a singularidade de cada um deles, pois entendemos que suas falas são representativas da estrutura racial na qual o branco paulista está inserido. 


\begin{tabular}{|c|c|c|c|c|c|c|}
\hline $\begin{array}{c}\text { Nome } \\
\text { Fictício }\end{array}$ & $\begin{array}{l}\text { Idade/ } \\
\text { estado } \\
\text { civil }\end{array}$ & $\begin{array}{c}\text { Cidade } \\
\text { de } \\
\text { Origem }\end{array}$ & Profissão & $\begin{array}{c}\text { Auto- } \\
\text { definição de } \\
\text { classificação } \\
\text { sócio- } \\
\text { economica }\end{array}$ & $\begin{array}{c}\text { Auto- } \\
\text { definição } \\
\text { Racial }\end{array}$ & $\begin{array}{c}\text { Origem da } \\
\text { Cor/Raça } \\
\text { (mencionados } \\
\text { por eles) }\end{array}$ \\
\hline Vinicius & $\begin{array}{c}55 \\
\text { Casado }\end{array}$ & $\begin{array}{c}\text { Diamante } \\
\text { - PB }\end{array}$ & $\begin{array}{l}\text { Vigia } \\
\text { Noturno }\end{array}$ & Classe baixa & Branca & $\begin{array}{l}\text { Brasil } \\
\text { Paraíba }\end{array}$ \\
\hline Lilian & $\begin{array}{c}6 \\
\text { Divorcia } \\
\text { da }\end{array}$ & $\begin{array}{c}\text { São Paulo } \\
\text { - SP }\end{array}$ & $\begin{array}{l}\text { Empregada } \\
\text { Doméstica }\end{array}$ & Classe baixa & Branca & $\begin{array}{l}\text { Brasil- } \\
\text { Bahia }\end{array}$ \\
\hline Marcelo & $\begin{array}{c}28 \\
\text { solteiro }\end{array}$ & $\begin{array}{c}\text { São Paulo } \\
\text { - SP }\end{array}$ & $\begin{array}{c}\text { Designer } \\
\text { Grafico }\end{array}$ & Classe Média & Branco & Italiana \\
\hline Fernanda & $\begin{array}{c}72 \\
\text { divorcia } \\
\text { da } \\
\end{array}$ & $\begin{array}{l}\text { Ourinhos- } \\
\text { SP }\end{array}$ & $\begin{array}{c}\text { Não } \\
\text { trabalha }\end{array}$ & Classe Alta & Branca & Portugueses \\
\hline Joao & $\begin{array}{c}38 \\
\text { Casado }\end{array}$ & São Paulo & Comerciante & Classe média & Branco & Portugueses \\
\hline Denise & $\begin{array}{c}30 \\
\text { Casada }\end{array}$ & São Paulo & Publicitária & Classe média & Branca & Italianos \\
\hline
\end{tabular}

\subsubsection{Repercussões do projeto eugênico na escolha matrimonial}

Para compreender como estes ideais eugênicos de incentivar a união entre os "geneticamente favorecidos" e produzir uma hereditariedade embranquecida analisamos algumas entrevistas com o intuito de identificar se havia nos sujeitos uma consciência que objetivasse a preferência pela branquitude, bem como um projeto de continuação, ou seja, um objetivo coletivo que projetasse uma continuidade da branquitude para o futuro, perguntamos, hipoteticamente, caso pudessem escolher a cor e traços físicos dos filhos, netos e continuação de suas famílias, se teriam alguma preferência e qual era o motivo de tal escolha. Os entrevistados, sem exceção disseram desejar ter filhos brancos.

Neste ponto, algumas dúvidas surgem: será que é a ideia de eugenia e de raça construída nos séculos XIX e XX é o que faz com que eles desejem ter filhos brancos? Ou, então, os sujeitos acreditam que realmente um filho não branco pode ser inferior geneticamente, moralmente e intelectualmente? E esta escolha se configuraria então eivada de traços racistas?

Aqui seria possível pensar que um projeto de descendência caracteriza uma construção de identidade grupal? Ou o racismo de nossa cultura faz com que estes tenham preferência por deixarem descendentes brancos? Ou então podemos pensar que o racismo é sim uma característica da identidade racial branca paulistana? Para maior compreensão disso analisaremos algumas falas dos entrevistados.

Vinicius tem 55 anos, trabalha na função de vigia noturno, mora em São Paulo, desde pequeno e não sabe as origens étnicas e 
nacionalidades de seus antepassados, por isso não faz diferença entre a cultura como algo relacionado à nacionalidade ou país de origem de seus antepassados. Quando perguntei sobre seus filhos e projeto de descendência, ele afirmou categoricamente que preferia branco:

\begin{abstract}
E: Se você pudesse escolher dos filhos pros netos, pra adiante, tua família, tua geração, você teria alguma preferência? R: Branco. E: Por quê? R: Eu gosto da minha cor, da cor dos meus filhos. Pra mim tá ótimo. Eu preferia a mesma coisa, se fosse pra começar tudo de novo, preferia a mesma coisa (Vinicius).
\end{abstract}

Desta forma, com o intuito de compreender se o discurso sobre a "superioridade racial branca" estava por trás desta resposta, investigamos o que era para ele ser branco, assim quando perguntamos a Vinicius o que é para ele ser branco, rapidamente ele sugere que é algo ligado a cor da pele e ao modo de agir:

E: O que é para você ser branco? R: Posso responder o que é
ser branco, eu gosto da minha cor e gosto das minhas
atitudes. E: Tem a ver com as atitudes? R: Não, vou dizer
assim, eu gosto da minha cor e gosto das minhas atitudes. O
que eu faço na minha vida, sou uma pessoa que trabalho,
não faço coisa errada, então gosto muito das atitudes da
minha sobrevivência, sempre tento fazer o bem, sempre
tentando as coisas certas.

Nota-se que a pergunta aqui se referia ao que para ele significava ser branco, e não sobre quais eram as atitudes morais que ele tinha cotidianamente, ou seja, ser branco para ele está ligado a características de atitudes e não a cor da pele. Assim, pensando nas preposições que Todorov (1993) elabora sobre a construção do discurso sobre as raças humanas, uma das características é acreditar que há uma continuidade entre o físico e o moral. Ou seja, Vinicius reproduz a ideia de que as raças não são apenas definidas por diferenças físicas, mas correspondem também a diferenças morais, psicológicas e intelectuais, e que dentro dos grupos raciais há as atitudes melhores, as quais "naturalmente" são dadas aos brancos. Pode-se notar também que as atitudes, que Vinicius relaciona à pergunta sobre o que é ser branco, estão ligadas a valores construídos pelo discurso eugênico como positivos em nossa cultura: trabalhar, lutar pela sobrevivência, fazer o bem.

Marcelo, apesar de negar que a raça esteja envolvida em suas preferências amorosas reafirma isto categoricamente, quando diz que em relação as preferência na hora da procura afetivo-sexual diz que:

R: Tem o lance da preferência na hora de escolha por mulheres. De você pegar mulheres com traços mais 
delicados, mais finos, com formas, corpo mais arredondado, com aparência mais angelical. Tem todo esse lado, mas daí tem mais a ver com relação homem-mulher do que uma raça assim especifica. (Marcelo). E: Hipoteticamente, se você pudesse escolher a cor e os traços físicos de seus filhos e netos, pensando numa continuidade da tua família, você tem alguma preferência? R: Bom, também tenho que ser honesto... A tendência, até porque vim duma família italiana, tem um peso assim, que não é explícito, mas acho que é meio psicológico, até da mídia que a gente tem, da coisa do belo, tender a ter criancinhas mais clarinhas. Acho que a coisa do negro bate sim nessa hora, principalmente, p'ra quem tem descendência europeia, que convive com pessoas brancas, que tem pouco convívio com pessoas de outra cor. Acho meio psicológico, acho meio natural até (Marcelo).

Para entender o que Marcelo quer dizer com cultura italiana e como ele associa estas características com atributos relacionados a uma "superioridade racial", perguntamos-lhe o que considera a causa das desigualdades raciais em São Paulo:

R: Eu acho que é a cultura. Por exemplo, minha avó é italiana, filha de italianos, ela veio da Itália, e eles eram pobres, mas sabiam como fazer tijolos, montaram uma olaria. Ganharam dinheiro, ficaram ricos. Minha avó foi trabalhar como faxineira de colégio público, criou três filhos sem pedir nada p'ra ninguém, colocou o lance da educação como a única solução p'ra eles saírem de uma situação desconfortável de limitação de roupa, comida, o próprio estudo. Então sempre impôs uma conduta ética, moral e de valores, que é o que fez toda diferença. Acho que é mais o lance da cultura, dos valores, da ética, da educação, do que um pai ensina p'ra um filho, do que a cor em si. E: Você acha que a coisa é cultural? O que é a cultura italiana?

R: Sim, eu tenho alguns conceitos que vêm da minha família. Parece-me que lá é assim. Tenho como base de valores o trabalho, o respeito às leis, o respeito ao próximo. Eles carregam esses valores. Fora a cultura cristã, que é a cultura do respeito ao próximo, tenho família muito católica, tem o respeito ao próximo, somos todos irmãos. Isso também soma muito p'ros valores e a conduta ética do ser.

$\mathrm{E}$ : Então, você acha que o fato de os imigrantes que vieram e conseguiram ter dinheiro, depois de três gerações, está ligada a cultura?

R: Sim, imagina, eles sempre estudaram, não são analfabetos, tiveram acesso às letras, às ciências matemáticas, eles tiveram acesso ao conhecimento. E quando eles chegaram aqui, se não tinham, foram construindo. Você não vê imigrante europeu sem estudar, sempre foi muito forte essa história do estudo, é um valor básico da sociedade deles. Diferente da cultura e dos africanos, que são mais flexíveis, quanto à ética e à moral, é só ver a religião deles, não tem esse negócio de fazer o 
bem... E eles dão mais valor para música, divertimento e essas coisas, enquanto o europeu, ao trabalho e estudo.

Aqui podemos perceber que Marcelo contrapõe aquilo que ele chama de cultura europeia ao que nomeia de cultura dos africanos. Todo o seu discurso relaciona as vantagens dos brancos como atributos morais, éticos e de condutas culturais intrínsecas aos imigrantes europeus. Para Marcelo, a explicação sobre as desigualdades sociais, que, para Vinicius, decorriam da ideia de raças superiores e inferiores, foi substituída pela de culturas superiores e inferiores, permanecendo a hierarquia entre a civilização branca europeia e as civilizações africanas. Desse modo, a ideia de "cultura", como aponta Guimarães (1999), transformou-se em uma noção tão fixa, estanque e estável quanto a de raça biológica.

Essa estrutura hierárquica entre culturas serve facilmente para um discurso étnico, sem precisar fazer referência explícita à raça e à cor. Neste discurso, são os brancos que aparecem como os mais civilizados, os mais cultos e com atitudes morais e éticas superiores. Mas esse modo de representação como próprio de civilizações europeias serve apenas para justificar o agudo contraste entre a população branca da população não branca, representada por Marcelo como analfabeta, com valores éticos e morais flexíveis e menos organizados, o que também daria estes uma maior aptidão para a música e o divertimento, enquanto os brancos teriam valores mais rígidos em relação ao trabalho, cumprimento de leis e ao estudo.

Em um mundo onde a ideia de civilidade e progresso está rotineiramente associada à cultura europeia e ao embranquecimento, fica difícil perceber estes discursos de nação e cultura em termos racialmente neutros ${ }^{3}$. Aqui é possível afirmar o considerável deslizamento de uma linguagem racista biológica para a cultural. Por outro lado, o discurso baseado em processos históricos e inclinações culturais pode ser, ao mesmo tempo, mais flexível, durável e com maior convencimento, pois oculta a discriminação racial pela justificativa cultural e mantém a ideia de superioridade moral, ética e intelectual que havia no discurso do racismo biológico construído pela LPHM. Dentro desse discurso, fica difícil imaginar a cidade de São Paulo sem a qual o branqueamento biológico e cultural seja visto como a única garantia de valores como modernidade e progresso.

Mesmo que o Brasil tenha como discurso o triunfo e orgulho da mestiçagem bem como o culto à morenidade, o que apareceu nas falas dos paulistanos ainda é o ideal eugênico construído pela LPHM, e que alguns mestiços com peles brancas são considerados brancos quando o que esta em jogo é a oposição aos negros, no entanto dentro do grupo dos brancos há características da mestiçagem que "mancham" esta brancura, ou seja, são considerados menos brancos. E aqui, penso que podemos denominar que há uma divisão que diz 
respeito ao que os sujeitos que se auto denominaram como de origem europeia na pesquisa chamaram de branco brasileiro, e o branco "original". Assim a fala abaixo, de uma entrevistada que diz ter origem europeia pode nos esclarecer sobre o que é esta diferenciação dentro dos brancos.

R: ...eu faço parte de um mundo que se eu fizer uma escova
no cabelo melhor ainda, que meu cabelo é ondulado. Se eu
colocar uma maquiagem, meu olho é claro, eu tenho cara de
europeia, não tenho cara de brasileira...Tem aquele branco
meio sujinho, né? Um branco brasileiro que, às vezes, até
tem olho mais claro, mas é meio encardido. Uma cor meio
assim suja, diferente do branco de verdade. O branco ralé é
o mestiço, é o sarará, é aquele que tem a pele branca e o
cabelo bem pixaim. A pele dele é branca, mas ele tem traços
de negro, então ele não é branco, é sarará... (Denise, 30
anos)

Nesta fala de Denise podemos identificar algumas facetas do ser branco no Brasil: a primeira é que o valor da branquitude, como afirma Sovik (2004) esta vinculada à origem étnica europeia e ao eurocentrismo e, portanto, há uma hierarquia entre os brancos, associada ao quanto um branco tem desta origem. Podemos perceber que o cabelo, os tons de pele branca, e os traços do rosto são os marcadores que apontam a falta ou presença desta origem. O fato de Denise achar que se fizer uma escova no cabelo estaria "melhor", pois os olhos e a pele clara ela já tem, significa dizer que o cabelo encaracolado lhe retira um pouco de brancura. Assim, como apontou que o branco de cabelo enrolado e com traços estereotipados, tal qual negro, não se afigura como modelo branco e, sim, sarará, ela nos mostra que o branco brasileiro é desvalorizado pela mistura com os negros e índios. Denise também aponta a mesma lógica em nacionalidades europeias que tiveram misturas ao longo do tempo, ou seja, há uma hierarquia entre as etnias europeias, e que arrisco dizer que é baseada em uma suposta ideia, imaginaria, de pureza e de mistura, como apontam as falas abaixo:

R: Meu irmão é moreno, não é mulato, mas é moreno, moreno do sul da Itália, bem moreno. Meu pai era moreno, mas pele clara, cabelo preto. Meu irmão cabelo preto, cabelo crespo que é do sul da Itália. E ele dizia: "ah, agora, a negro nesta casa sou eu!" Porque ele tinha um cabelo crespo, bem crespo, mas no sul da Itália está cheio, e vem de onde? Vem da África! Aquela mistura! mas ele é branco. E: Quando você acha que a pessoas deixa de ser branca, qual é essa fronteira? R: É a cor. Tem beiço, tem a cor das mucosas, é ter um pé na cozinha, né, essa famosa frase, "ah, aquela família tem pé na cozinha". E: E você acha que tem diferença entre os brancos? Há um branco que é mais branco? R: O meu privilegio, eu diria que foi muito mais 
internacional, eu não fui discriminada fora, nos EUA. Hotel... teve brasileiro branco que chegou em hotel e foi posto para fora. Você sabe disso. Eu não corri riscos sendo branca tipo europeia. Branca, branca, risco de ser tomada por mestiça... qual é a fronteira que separa? A mestiçagem. ( Fernanda)

E: Quem é branco para você?

R: Quanto mais limpa a genética vinda da Europa, você tem o branco mais puro, tipo propaganda de sabão em pó. Que vem do norte da Europa e Rússia, aquela região. Eu sou bem branco, deve ser a descendência russa, Norte da Europa é diferente do sul, norte e sul da Itália, por exemplo, no sul as pessoas são mais morenas, cabelo mais enrolado, por exemplo, tem gente misturada da invasão dos otomanos. No norte já são mais "suíças", por exemplo, no sul as pessoas são mais morenas, e já é tudo mais bagunçado mais desorganizado. Você pode ver da suíça para cima onde não teve mistura é tudo melhor. O Branco brasileiro não é tão branco, não é branco puramente branco. Mesmo porque o branco brasileiro descende de Portugal e o português é misturado, sempre foi colônia de férias de outros povos, da áfrica, dos árabes. (Marcelo)

Nas falas de Marcelo, Denise e Fernanda é possível perceber que os paulistanos descendentes de imigrantes europeus não se consideram como misturados, ou como não brancos, como propaga o discurso sobre mestiçagem no Brasil, tão bem enunciado na musica Olhos Coloridos (1994) de Sandra de Sá: "A verdade é que você, todo brasileiro tem! Tem sangue crioulo, tem cabelo duro, sarará, sarará, sarará, sarará, sarará crioulo". Ao contrário disso, aqueles afirmam uma branquitude sem misturas, e ainda, uma branquitude melhor, pois vem de etnias que, diferente da portuguesa, não se misturou com outras. E assim, apesar de brasileiros, estes apontam que há um branco que é branco só no Brasil, mas lá fora não é. Não à toa, Fernanda e Denise disseram que tiveram facilidades para circular na Europa, que outros brancos brasileiros não tiveram. Aqui percebemos a fluidez da raça na própria fala dos sujeitos. E cabe perguntar, qual é a fronteira que faz com que percebam que alguns fazem parte da branquitude paulistana, mas não fariam parte da branquitude de países Europeus ou dos Estados Unidos?

Marcelo responde definindo que há uma hierarquia nas nacionalidades europeias que está relacionada às nacionalidades que em seu ver tiveram misturas e outras que não tiveram, e que as que não tiveram também demonstram melhor organização e uma "superioridade cultural" as que se misturaram. E, também, que esta hierarquia de nacionalidades é associada diretamente a uma hierarquia de fenótipo conforme descrita por Denise, que classificou as diferenças entre os brancos, chegando ao fenótipo mais branco, o alemão: 
E: Você consegue pensar uma escala de brancos? R: Consigo. Tem o branco que a pele é branca, o cabelo é escuro e crespo. Tem o branco que tem o cabelo escuro, mas liso, olho claro. Tem um branco que tem cabelo castanho claro, mas crespo. Acho que o cabelo crespo tá sempre pior, o cabelo liso é o sonho de consumo. E: E os traços? R: Os traços, a medida que o nariz vai ficando menor e mais fininho, vai ficando mais branco. Apesar de que italiano tem narigão, enorme pra frente. Mas eu acho isso, dai vai dar num alemão, se você for p'ra Alemanha, tu vai ver que as pessoas tem o nariz menor, mais fininho tal. $O$ branco mais puro é loiro de olho claro... Que horror, né! É um conceito muito nazista, de raça pura. Mas é assim que eu vejo. (Denise)

Nesta mesma lógica de Denise é necessário entender que o que está em jogo, quando se fala de mistura e mestiçagem, não diz respeito às misturas étnicas, pois a mistura entre brancos, não é como misturas, Fernanda aponta quando diz que os italianos do sul são morenos porque possivelmente se misturaram aos africanos, ou quando Marcelo diz que Portugal era colônia de férias de Africanos e Árabes. Pois, quando um branco, de origem alemã se mistura com um branco de origem francesa isto não é visto como mistura, nem tão pouco quando um negro da nação Angola se mistura com um negro da nação Yorubá. Mais uma vez, fica claro que neste imaginário construído a partir da ideologia racial há graus de brancura, e que a desvalorização hierárquica está associada aos sujeitos que, apesar da pele clara, apresentam características de negros e índios. Esta ambiguidade projetada no fenótipo dos sujeitos não é percebida somente por brancos que se autoidentificam, apenas, com a descendência europeia, mas também, nas falas dos mestiços brancos, que muitas vezes não fazem ideia de sua origem. Mas sabem que não são tão brancos, quanto outros, como caso de Lilian e Vinicius:

R: Já falaram que eu sou negra, porque eu tenho os lábios grossos, o nariz, bunda grande, sabe, falam: ah você é uma branca negra, já falaram isso, mas eu nunca procurei estudar, aprofundar. Mas nesse ponto acredito também que existe o negro que é branco, tipo estes de lábios e nariz finos eu por exemplo sou branca mas sou um pouco negra por causa do nariz boca, sabe, do porte físico (Lilian).

$\mathrm{R}$ : Ah tem vários tipos de brancos, eu sou aquele branco meio encardido né? Eu nem sei de que origem eu sou, sei que sou branco e meus parentes sempre contaram historias da Paraíba acho que sempre foram de lá, e tem alguns que vieram pra cá pra São Paulo (Vinicius).

As falas acima mostram que a própria branquitude tem fronteiras que são construídas, através da categoria raça produzida pelo século XIX 
pois as características presentes nas falas acima dos sujeitos como aquelas que "mancham" a branquitude de alguém estão ligadas ao fenótipo dos sujeitos e são hierarquizadas exatamente a partir da noção de raça produzida pela ciência no século XIX. Um exemplo disso é a fala de João sobre as diferenças entre o que ele chama de branco e de nordestino:

R: Tem muito nordestino branco. Mas nordestino para mim não é branco, é nordestino. É uma mistura geral de português, índios e negros. O nordestino não é que nasceu no nordeste, mas sim uma mistura, por exemplo, o cantor Otho nasceu no nordeste, mas não é o que eu chamo de nordestino, ele tem cara de branco europeu, já o branco nordestino tem cabeça chata, é baixinho, uma outra coisa (J oão).

A fala de João que define nordestino por características fenotípicas e nao pelo nascimento e pertencimento à região brasileira do nordeste pode nos ajudar a pensar que tanto os estereótipos quanto 0 preconceito do paulistano sobre o nordestino pode estar associado ao racismo, pois o que é que faz com que João retire a nordestinidade do cantor e compositor recifense Otho (ruivo de olhos claros) e não daqueles com características físicas que João define como uma mistura entre português, índios e negros? Neste caso, a retirada de Otho do grupo nordestino por João nos mostra que este apagou e neutralizou a história e ligação do cantor com esta cultura e regionalidade em prol de um olhar racializado onde a anatomia é o destino. Em contrapartida, Vinicius, paraibano residente em São Paulo, que durante sua entrevista afirmou que brancos tem atitudes melhores que negros, se autoclassificou como branco encardido, mostrando que, mesmo se sentindo parte da branquitude, sabe que há graus de brancura, e que na lógica racializada, ele é menos branco que outros.

A partir destes discursos, podemos pensar que o que ocorre é que nossa sociedade se apropriou dos significados compartilhados sobre superioridade e pureza racial dos brancos, e desta forma desenvolveu um sistema hierárquico silencioso e camuflado de atribuição de status social que desvaloriza as pessoas na proporção em que essas se afastam do modelo ideal de brancura, representado aqui nas falas dos sujeitos como tom de pele muito claro, cabelos lisos e loiros, traços finos, e olhos claros, e que também representa no imaginário aqueles que vieram da Europa.

Assim percebemos que a crença numa "superioridade branca", aclamada pelos nossos intelectuais nas primeiras décadas do século $X X$, ainda fazem eco e produzem sentidos na sociedade paulistana contemporânea; nesse sentido, as frases de alguns entrevistados parecem repetição dos discursos daqueles médicos de quase um 
século atrás. Assim, podemos pensar que os discursos construídos pela LPHM, ainda fazem parte do imaginário e do ideal de nação, progresso e desenvolvimento que os paulistanos de hoje constroem como significativos para suas escolhas afetivas, construção de família bem como ideal de moralidade, atitudes e formas de identificação.

Assim propomos que outras pesquisas sejam feitas por psicólogos e cientistas sociais com o intuito de investigar de que modo possa ser desconstruídos os valores de superioridade racial branca que foram naturalizados e apropriados pelos sujeitos paulistanos como nossas entrevistas apontam.

\section{Referências}

ANTUNES, E. H. Raça dos gigantes: a higiene mental e imigração no Brasil. In: (Org.). ANTUNES, E. H.; BARBOSA, L. E. S.; PEREIRA, F. M. F. Psiquiatria, loucura e arte: fragmentos de história brasileira. São Paulo: Edusp: 2002.

ANTUNES, P. C. A. Eugenia e I migração. 1926. 83f. Tese (Doutorado) - Faculdade de Medicina e Cirurgia de São Paulo, São Paulo.

DIWAN, P. Raça pura: uma história da eugenia no Brasil e no mundo. São Paulo: Contexto, 2007.

DOMINGUES, H.; SÁ, M.; GLICK, T. (Org.). A recepção do darwinismo no Brasil. Rio de Janeiro, Editora Fiocruz, 2003.

COLLICHIO, T. Miranda Azevedo e o darwinismo no Brasil. Belo Horizonte/ São Paulo, I tatiaia/Edusp, 1988.

COSTA, J. F. História da Psiquiatria no Brasil: um corte ideológico. 5 ed. Rio de Janeiro: Garamond, 2007.

FRANKENBERG, R. A miragem de uma Branquitude não marcada. In: WARE, Vron (Org.). Branquidade: identidade branca e multiculturalismo. Rio de J aneiro: Garamond, 2004, p. 307-338.

GILROY, P. O Atlântico negro: modernidade e dupla consciência. Trad. Cid Kinipel Moreira. Rio de Janeiro: Editora 34, 2001. - One Nation Under a Groove. In: Small Acts: Thoughts on the Politics of Black Cultures. London, 1993.

GONÇALVES, A. I magens retóricas e iconográficas das campanhas de saúde pública em São Paulo. In: ODALIA, N.; CALDEIRA, C. (Orgs.). História do Estado de São Paulo/a formação da unidade paulista. v. 2. República. São Paulo: UNESP; Imprensa Oficial; Arquivo Público de Estado, 2010.

GUALTIERI, R. C. E. O evolucionismo na produção científica do Museu Nacional do Rio de Janeiro (1876-1915). In: DOMINGUES, H.; SÁ, M.; GLICK, T. (Orgs.) A recepção do darwinismo no Brasil. Rio de Janeiro: Editora Fiocruz, 2003, p. 45-96. 
GUIMARÃES, A. S. A. Racismo e Anti-Racismo no Brasil. Rio de Janeiro, Editora. 34, 1999.

LOBO, L. F. Movimento eugênico: tribunal de todos os desvios. In: J ACÓ-VILELA, A.; CEREZZO, A.; RODRIGUES, H. (Org.) Clio-Psyché Ontem - Fazeres e dizeres psi na história do Brasil. Rio de Janeiro: Relume Dumará, 2001, p. 45-55.

MARINHO, M. G. A Fundação Rockefeller e instituições de ensino e pesquisa em São Paulo. Bragança Paulista: Horizontes. v. 22, n. 2, p. 151-158, Jul/Dez 2004.

- Norte-americanos no Brasil: uma história da Fundação Rockefeller na Universidade de São Paulo (1934-1952). Campinas/Bragança Paulista/SP: Autores Associados/Editora da Universidade São Francisco/FAPESP, 2001.

MARQUES, V. A medicalização da raça: médicos, educadores e discurso eugênico. Campinas: Unicamp, 1994.

MONTELEONE, P. Os cinco problemas da eugenia brasileira. 1929. 161f. Tese (Doutorado) - Faculdade de Medicina e Cirurgia de São Paulo, São Paulo.

MOTA, A. História Regional e o Sanitarismo na Republica Velha. Publicação do Departamento de História e Geografia da Unive. Centro de Ensino Superior do Seridó - Campus de Caicó. v. 7, n. 17, ago./set. 2005a - Semestral. ISSN -1518-3394. Disponível em: $<$ www.cerescaico.ufrn.br/mneme>. Acesso em: 15 ago. 2011.

MOTA, A.; SCHAIRAIBER, L. (Org.). I nfância e Saúde - perspectivas históricas. São Paulo: Hucitec, 2009.

MUNANGA, K. Rediscutindo a Mestiçagem no Brasil: identidade Nacional versus identidade negra. Belo Horizonte: Autêntica, 2004.

NARITA, S. Notas de pesquisa de campo em psicologia social. Psicologia Social, Porto Alegre, v. 18, n. 2, ago. 2006.

PACHECO E SILVA, A. Conferência proferida no I Congresso Brasileiro de Eugenia. Rio de Janeiro, [ca.1929].

- Direito à saúde no Brasil (documentos de atividade parlamentar). São Paulo: Acervo do Museu Histórico Prof. Carlos da Silva Lacaz, FMUSP, [s.n.], [ca. 1934].

Discurso pronunciado como paraninfo na cerimônia da colação de grau dos doutorandos da Faculdade de Medicina da Universidade de São Paulo. Revista dos Tribunais, São Paulo, 1939.

. Higiene Mental. São Paulo: Acervo do Museu Histórico Prof. Carlos da Silva Lacaz, FMUSP, [entre 1934 e 1954].

. I mpressões do Congresso Internacional de Psiquiatria Infantil e Higiene Mental. São Paulo: Acervo do Museu Histórico Prof. Carlos da Silva Lacaz da FMUSP, [ca. 1937].

O dia da raça. São Paulo: Acervo do Museu Histórico Prof. Carlos da Silva Lacaz, FMUSP, [ca.1934]. 
O exame pré-nupcial. Palestra proferida na Rádio

Difusora. São Paulo, 20 junho, 1936.

REIS, J. R. F. De pequenino é que se torce o pepino: a infância nos programas eugênicos da Liga Brasileira de Higiene Mental. História da Ciência Saúde-Manguinhos, v. 7, n. 1, p. 135-57, jun. 2000.

SCHWARCZ, L. O Espetáculo das Raças: Cientistas, Instituições e Pensamento Racial no Brasil: 1870-1930. São Paulo: Companhia das Letras, 2008.

STEPAN, N. A Hora da Eugenia - raça, gênero e nação na América Latina. Rio de Janeiro: Fiocruz; 2005.

STEYN, M. Novos matizes da "branquitude": a identidade branca numa África do Sul multicultural e democrática. In: WARE, V. (Org.). Branquidade: Identidade branca e multiculturalismo (Tradução: Vera Ribeiro). Rio de Janeiro: Garamond, 2004, p. 115-137.

SOVIK, L. Aqui ninguém é branco: hegemonia branca no Brasil. In: WARE, V. (Org.). Branquidade: Identidade branca e multiculturalismo (Tradução: Vera Ribeiro). Rio de Janeiro: Garamond, 2004, p. 363-386.

TODOROV, T. Nós e os outros: a reflexão francesa sobre a diversidade humana, v. 1. Rio de Janeiro: J orge Zahar, 1993.

\section{Endereço para correspondência}

Lia Novaes Serra

Endereço: Rua Capote Valente, 1368. Cep: 05409-003, Pinheiros, São Paulo, SP

Endereço eletrônico: lianovaesserra@gmail.com

\section{Lia Vainer Schucman}

Endereço: Barão de Bananal, 786, ap. 3. Cep: 05024-000, Pompéia, São Paulo, SP

Endereço eletrônico: liavainers@gmail.com

Recebido em: 06/10/2011

Reformulado em: 15/04/2012

Aceito para publicação em: 15/04/2012

Acompanhamento do processo editorial: Ana Maria Jacó Vilela

\footnotetext{
Notas

* Graduada em Psicologia pela Pontifícia Universidade Católica de São Paulo (2007), com aprimoramento em Unidade Básica de Saúde pela Faculdade de Saúde Pública/USP (2010). Mestrado em Psicologia Social e do Trabalho, pelo Instituto de Psicologia/USP (2011). Atualmente, se dedica ao estudo da história da psicologia e da psicanálise.

**Graduada em Psicologia pela Universidade Federal de Santa Catarina (2003) e Mestrado em Psicologia pela Universidade Federal de Santa Catarina (2006). Doutorado em Psicologia Social na Universidade de São Paulo, cumulado com período como visiting resercher no center for new racial studies da University of California Santa Barbara. Tem experiência na área de Psicologia, com ênfase em movimentos sociais, atuando principalmente nos seguintes temas: identidade, movimentos sociais, raça, racismo, branquitude e psicologia social.
} 
${ }^{1} O$ país reafirmava sua importância na divulgação dos preceitos higiênicos ao realizar o I Congresso Internacional de Higiene Mental, em Washington no ano de 1930.

${ }^{2}$ Estas entrevistas são parte da pesquisa de doutorado de uma das autoras deste texto. A pesquisa se refere a constituição da branquitude paulista na contemporaneidade, e teve como procedimento investigar a categoria raça na constituição de sujeitos brancos

${ }^{3}$ Sobre a maneira como o discurso sobre identidade cultural permite a fusão entre raça e nação, ver GILROY (1993, p. 357), One Nation Under a Groove, In: Small Acts: Thoughts on the Politics of Black Cultures, London; e; GILROY (2001), O Atlântico negro: modernidade e dupla consciência. Trad. Cid Kinipel Moreira. Rio de Janeiro: Editora 34. 